\title{
What Children Mean to Their Parents: A Qualitative Approach
}

\author{
JUHA HÄMÄLÄINEN \\ Assistant Master \\ Department of Education \\ University of Jyväskylä
}

\section{Introduction}

This article is based on a broader research study into the sociology of the family where the writer examines changes experienced in their lives by the parents of a baby in connection with their transition into parenthood. One theme of the study was the meaning attached by parents to their children, a theme which will be pursued further in this article. The description presented in this article will not be connected to the model depicting the transitional process into parenthood as described in the study. Instead the significance attached by parents to their children will be studied as a separate entity.

Parenthood is a very intricate and complex object of research. It may be studied from at least the following points of view: the sociological, the anthropological, the psychological, the educational, the social political, the biological, the medical, and the demographic. The question of what children mean to their parents clearly has a demographic and social political dimension. The significance of children is conceptually linked to the motives for having children, to why people want to have children, and why they have them.

\section{The theoretical background of the study}

Modern parenthood is associated with a long-range planning on the part of the parents. The development of contraceptives and the relaxation of the taboos connected with them have made it possible for parents to choose when they wish to have children and how many they wish to have. The values, according to which people make these choices are, in part, at least, dependent on the expectations of the surrounding culture (amongst others Rossi, 1968, 30). It is a fact, though, that people do not simply react passively to the expectations of their environment; instead they participate actively themselves in forming their values and roles in interaction with their social environment (cf. Blumer, 1969; Rock, 1979).

Symbols are of central importance in attempting to understand human behavior. People decide what to do and what not to do primarily on the basis of the symbols they have learnt in their interaction with other people and on the basis of the beliefs they have regarding the importance of these symbols. Thus the significance of children to their parents becomes one of the central elements in the examination of their motives for having children in the frame of reference provided by symbolic interactionism. In the paper upon which this article is based the theoretical point of view afforded by symbolical interactionism has been regarded as the point of departure

${ }^{1}$ Forthcoming. The writer of this article possesses the manuscript. 
in the formation of a frame of reference. (cf. Blumer, 1969; Burr, Leigh, Day and Constantine, 1979).

From the viewpoint of symbolical interactionism the acquisition of children on a voluntary basis is based on the premise that people desiring a common child attach to children (i.e. to parenthood) values which they consider worthwhile. In the final analysis these values, be they instrumental or inherent values, act as criteria employed in choices regarding child-bearing (pursuit of parenthood). The values connected to having children are part of each individual's personal set of values, which has always been shaped through symbols learned in the process of social interaction.

In the research literature on the sociology of the family, the values associated with the aspirations of parenthood have been classified, for example, in the following manner:

1. Reinforcement of the adult status and of the social identity associated with it. According to Rossi (1968) motherhood in particular is regarded as the fulfilment of a woman's life and as the confirmation of her adulthood.

2. The continuation of one's life in relation to one's own personality.

3. The achievement of such moral values as are respectively regarded in each culture in question as pertaining to parenthood.

4. The formation of a primary grouping which affords several opportunities for close affectionate relationships. LeMasters (1974) also refers to the commonly held belief that a childless nuptial relationship is frustrated and unhappy.

5. Closely related to the previous point: A child brings with it an energetic boost to the lives of its parents, novelty, and fun.

6. The fact that something has been achieved, that some capacity has been demonstrated and satisfaction achieved in this regard in connection with the birth of the baby.

7. An increase in one's power through the acquisition of a child over whom one can exert this power.

8. Social competition and the comparison of oneself to others; connected with this the belief that one's own child has the criteria to produce advantage and satisfaction in this regard.

9. Economic gain - especially in primary production, a family business or in the case of parents advanced in years.

There may be significant differences, both between individuals and cultures in the emphases accorded these values and in the relationship between them. (Hoffman and Hoffman, 1973; in Rapoport, Rapoport and Strelitz 1977, 139-140)

Research into the values associated with the aspirations to parenthood and into the significance attached by people to parenthood (i.e. to children) is concerned with qualitative phenomena. Symbolical interactionism provides a theoretical frame of reference for qualitative research into parenthood. The qualitative perspective will in all probability provide significant additional information also to theory formation in the field of demography, a field traditionally based on material collected quantitatively and on its statistical-mathematical processing and presentation.

\section{Research problem}

In connection with this article, one problem rises to the fore, viz. What do children mean to their parents? This problem will not be sub-divided into more detailed sub-problems.

\section{Object of research}

The object of research was a random choice of 40 couples from Jyväskylä and 
its surroundings with a baby aged 3-5 months in the family. Half of the couples were couples with just the one child.

\section{Method of research}

The method of research employed was free group interview, an approach analogical to the group interview employed in »clinical» family therapy. In research, as opposed to family therapy, the aim is the systematic collection of data on the subject being studied. Amongst those who have used free group interview in their research on the sociology of the family are LaRossa and LaRossa $(1977,1981)$ who had as their aim the qualitative description of certain phenomena of family life.

The method of research was chosen so as to enable the making of qualitative observations of the object of research. To this end observational data was collected, this comprising authentic quotations from the individuals concerned, regarding subjectively experienced or subjectively given meanings, in this case the significance of children to their parents. In these quotations, meaning appears external to the subject, on the level of observations, this making possible their objective description.

In practice, in the interview situation, the parents were asked what their children meant to them in their lives and in their family thinking and why they wanted or had wanted children. This question was answered freely, the parents describing the significance given their children by them and their own subjective feelings for the children. These feelings were in fact values attached by the parents to children and to parenthood. According to the theoretic basis for this study, symbolic interactionism, these significances and values are central factors in explaining human behavior, in this case, the bearing of children.

The processing of the data comprised both quantitative (statistically descriptive) and qualitative (verbally descriptive) examination. For the purpose of quantitative analysis variables were constructed, which in turn were collected into a framework for a quantitative analysis of the content. In the conceptual analysis of the data and in the making of summative conclusions abductive inference, bases on the interaction between induction and deduction was employed. The following sources were of help in the analysis of the data:

1) Hoffman and Hoffman's (1973) classification of values connected with the aspiration to parenthood

2) LaRossa and LaRossa's (1981) differentiation between the internal and external values of parenthood.

\section{Validity of the data}

The better the results of qualitative research correspond to the real situation in the empirical world, the more valid the research is. A prerequisite for this external validity of research is the obtaining of the most truthful information as possible from parents regarding the meaning their children have for them. It is essential in this regard that the research worker has been able to draw the correct conclusions from the interview material. Internal validity is concerned with harmony between the conclusions obtained and the concepts used. (amongst others Grönfors, 1982)

The advantage of the free interview realized in the form of a conversation is that the interviewees have the opportunity to answer the questions put to them according to their own schemes of thought, as broadly, deeply and from as many points of view as they themselves see fit. The validity of interview research can be improved by paying particular attention to concepts, meanings and language usage in general. Contents of meaning have been of central importance as foci of attention, both in the interview situation and in the analysis of the material. Both the interviewer and 
the interviewee has the opportunity during the interview to ask further, more precise questions of each other; this has helped increase the validity of the material.

Research based on group interview provides information confirmed by both interviewees. In investigations of the meaning children hold for parents this factor probably possesses no significance adding to the validity of the corpus, because the experience of being a parent is very subjective. A possible disadvantage of this approach, however, is the case where the thoughts expressed by one of the parents possibly bring elements into the expressions of the other, which would normally not have been there.

Two problems of validity may be distinguished in the study:

(1) Do the expressions employed by the parents correspond to the ideas really held by them?

(2) Do the inferences drawn by the researcher correspond to the concepts and experiences really felt by the parents regarding the significance of the children?

It was not possible in the scope of this study to investigate the existence or lack of systematic errors possibly connected with the former problem. The role of possible random errors in the comments of the parents and in the inferences thus drawn was examined on the basis of the inner consistency of the data. Without exception the material proved to be coherent and internally consistent.

\section{Findings}

When asked during the interview why they wanted children, many parents found that it was the first time they had really had to give the matter any thought at all. Couples who had had difficulties in getting children, had, on being faced with the possibility of childlessness, pondered over the meaning that children had for them to a greater extent than the average parent.

The material from the interviews demonstrated the fact that the motives that people profess for parenthood, and the meaning children have for them, are many and varied. Despite differences in the value and motive systems of the parents interviewed regarding their having children and regarding the meaning accorded to children, the material seems to indicate several common features. The experiences and views of parents were in part very similar to each other.

\section{Meaning in terms of instrumental and inherent value}

Generally speaking, the significance given children by their parents may be divided into two groups: instrumental and inherent value. Table 1 gives a comprehensive presentation of the main categories of descriptions regarding the meaning imparted to children.

The categories presented in Table 1 are very general in nature and their individual contents are often inextricably intertwined in the experience of the people concerned. Thus, in describing the meaning their children had for them different parents would allocate the same intity of thought differing categories of content. For instance, the idea of children being a natural part of life and on the other hand attaching the meaning of life to the having of children are, on more general examination, two sides of the same thing. Similarly, the demonstration of one's worth as a human being through the bearing of a child (through parenthood) is a logical link in the train of thought, whereby children have a natural place in the life of a normal adult. Similarly the continuation of life in one's children may receive a meaning closely related to the meaning of life.

For instance the intertwining of the categories of meaning is to be found in the following expressions culled from the interview material: 
T a b l e 1. The significance given children by their parents $\left(n_{c}=40\right)$.

Category depicting significance of child

A. Inherent meanings

1. The perpetuation of life in one's children

2. Attachment of content and meaning of life to one's children

3. Children as a natural part of life and of the relationship between a married couple

B. Instrumental meanings

1. Children are nice; they bring stimulation to life

2. Children as an avenue to the demonstration of one's human worth, reinforcement of one's adult identity

3. The strengthening of the marital (and familial) relationship

4. Children as support in old age

$\mathrm{n}_{\mathrm{c}}=$ the number of couples

$f_{c}=$ the number of couples of whom at least the husband or the wife has given children the meaning mentioned to the left of the table.

"I feel that a rich life is to be found in this area. When one has lived for a time with one's spouse, there arises a longing for children. It is, nevertheless, a spurt forward in life, and man is the kind of creature who always wants to go on. . .

When you come to think of what life is all about, you wonder whether it is to have children. I mean this chance has been given to us, a chance to carry on the family.»

(man, 26, 1 child)

"It's normal, isn't it, when one gets to the age when one understands this sort of thing .... in principle, I suppose everybody thinks of finding the right one and establishing a family .... in one's innermost everybody must want this and a child is its fulfilment ...

... This life of ours has no meaning, if we have no one to continue it ... you accumulate something and then you have someone to leave it to . . . at least I think that a man's life is empty if there's no family or children . . . it's every normal person's ambition in life. Even though it seems that society today doesn't consider it that important any more.»

(man, 33, 1 child)

The classification of parents' meanings into instrumental and inherent was problematic in that this dichotomy in many cases did not offer a suitable intermediate form: meanings may include both instrumental and inherent meaning.

Compared to the list by Hoffman and Hoffman (1973) of values pertaining to the attainment of parenthood the emphasis in this study was on $»$ the natural role of children as part of life and of the parental partnership» and sthe attachment of the content and meaning of life to children». Neither of these values was mentioned in the earlier list which was apparently compiled unaccompanied by empirical research.

According to this study, the significance of children to their parents seems to be associated, in the field of the sociology of the family, with the emotional function and the procreational function of the family. By reinforcing the feeling of affinity between the parents, the children create a feeling of closeness in the reciprocal relations, thus adding to the degree of cohesion in the family. The parents feel their children to be a continuation of their own existence, a continuation of life in general. This factor seems to have some kind of function associated with mental health or the emotions. Similarly, the association of children with the meaning of life assumes a meaning in the emotional domain of human experience. 
Of the meanings mentioned in Table 1, parents of first-born children give the reinforcement of their mutual relationship significantly more often than parents of second or third children. $\left(\chi^{2}=5.18, \mathrm{df}=1, \mathrm{p}<.05\right)$. In other meanings mentioned by the interviewees, no statistically significant differences were noted between parents of firstborn children on the one hand and parents of second or third children on the other.

\section{Children as providers of purpose and direction in life}

In the comments of parents interviewed, children often seem to signify in one way or another a main sense of purpose in their human existence and in life. Children give life a sense of purpose in at least the following ways:

- by creating the feeling of continuation

- by giving a feeling of sense and direction to life

- by making the parents responsible for the child into important, meaningful individuals,

- by making the couple into a family, by enriching the partnership relation and reinforcing it and

- by giving the feeling that one criterion of human existence has been fulfilled.

Above all, a child seems to signify new content and meaning in life, as well as new responsibilities for the parents. Having a child of one's own gives a person's existence a new meaning which finds expression in an increase in the purpose of life. The latter may be reflected in turn in different spheres of life, as was demonstrated in the paper upon which this article is based.

Let it be emphasized that when we are talking about »the meaning of life», we are talking about a concept which is part of the everyday thinking employed to express the meaning children have for parents and the experiences of parenthood. As may be seen in the following extracts from the corpus, the meaning of life has pride of place in the parents comments:

»It is fulfilment in life. Life à deux has its positive aspects, but it isn't everything. Personally I feel that children give meaning to my life, something I have felt in a concrete way in the past few months. In other words, the whole family has an extremely great part to play, even if there are a lot of problems. You can see generations go and life continuing. This might be a feeling even more profoundly experienced by grandparents: somehow the meaning of life is emphasized in children.»

(man, 31, 2 children)

»Well, yes; I do think life lacks sufficient meaning on one's own; or even if one was married but without kids. Children usually are the aim. A childless couple will easily drift into living just for themselves. At least I feel I need different aims and motivations, a child is very important in that regard. Just being married is not enough to motivate a person to effort in life. Children are the basic prerequisite for the hope that there will be someone to carry on in the farm and enjoy the results of what one has done oneself.»

(man, 23, 1 child)

"A life's work ... It's something one has in common (in the mutual relationship) . . . I think it gives you a kind of content, and then later you have the responsibility, there's no end to it, there's always someone who needs you ... you don't feel you're not needed.»

(woman, 28, 1 child)

"Yes, it's all the world to me: there isn't a thing I wouldn't do for the child.

There's a meaning to this life, what you work for ....»

(man, 27, 1 child) 
»I mean, imagine there just being the two of us flitting along in this world ... there must be some meaning to life, and I think that it's to have a family, to care for the children and observe them growing, because there is something of oneself there: you sacrifice and give of yourself quite gladly. When we thought we wouldn't get a child, it kind of frightened us, the thought that there'd just be the two of us staring at each other. Growing old together was a frightening thought, so monotonous . . . A child is what you work and pull together for; working together and bringing the child up, that's what strengthens the marital relation.»

(woman, 24, 1 child)

Some parents seemed to reject the view that parenthood was a »measure of humanity» or some sort of »fulfilment of life». In this regard they sometimes mentioned the fact that not all adults could have children; some had also chosen to live alone and to get a meaning for their lives from things other than being parents.

\section{Children as a natural part of life (and the mutual relationship)}

In describing their children as a natural part of life, parents were referring, in addition to their philosophy of life, to the fact that man has a natural need to protect and take care of little children, a natural longing to have children and a need to see life continue. Even though it is usually not practicable to compare the answers of individuals obtained from qualitative material through an interview of a couple, let it be stated that almost as many men (7) as women (10) mentioned the natural instinct to care for children as a factor in having one's own children.

On the basis of the data it seems that in planning their families, people do not so much consider whether they want children in the first place as when and how many children they want. To be true, the people interviewed were a select group: the domain comprised only such cases as had had children. Several of the parents who had participated in the interview regarded children as belonging to life and the marital relationship to such an extent, that in their view the lack of children would be the lack of something quite essential from life and the family. Some assumed that they could not actually live without children. Many also thought that children helped to give the relationship between a couple a sense of purpose and make it lasting.

The interview data contained a large number of descriptions to the effect that the interviewees felt that children were a part of life (the relationship between the couple) and gave it a sense of purpose. The following samples have been selected from these descriptions:

"Somehow it seems that they are part and parcel of the family: ... when you get married you feel you want children ... somehow they seem an essential part of marriage; a family isn't quite a family until they have a child . . . they're an essential part of the whole.»

(woman, 21, 1 child)

"You don't feel you're a family until you've had your first child." (man, 26, 1 child)

"When you get married and are together with your husband, you must have children. It's a kind of natural result of living together.»

(woman, 22, 1 child)

"You must admit, until there are children, there's no family.»

(man; 32; social educator, a qualification for children's home workers, day care center directors, kindergarten directors, addict rehabilitators; 1 child)

"Somehow I've grown up with the thought that there are children in a family . . . otherwise it's not a family.»

(woman, 26, 1 child) 
"At least I think a family is somehow not complete without children. They're a most natural part of the family. Children are part of what life is all about, about life going on.»

(woman, 21, 1 child)

"It's kind of natural. Generally people who get married have children. I couldn't imagine us not having children. They make a family into a family. ... I've always thought that way, even before I was married. All my life I've thought that one must have children. Children are a part of life.»

(man, 37, 3 children)

The parents who, in evaluating the significance of their children, mentioned the strengthening of the bond between them as one factor, were, with the exception of one couple the same parents who included in their descriptions thoughts about children naturally belonging to life and the marital partnership and who expressed the role of children in the formation of the actual family.

\section{Parenthood as a boost to one's self-concept}

The corpus leads us to assume that the birth of a child to many parents signifies the achievement of a certain station or status. In this sense the having of children is often associated with achievement motives: through one's children one can demonstrate one's adulthood, independence, worthiness or the tenability of the marital partnership. In addition to these achievement motives there seems to be the aspect of self-respect which links the having of children to the parents' self-esteem. Generally speaking, the achievement motives associated with the having of children are probably more emphasized in the case of primiparity compared to those giving birth to their second or third child. It was not, however, possible to obtain confirmation of this within the scope of this study, since the question regarding the parents' motives in having the child was asked in a general manner during the interview, with no particular focus on a child born just before the point of time of the interview. The only information the interview provided was whether the child born just prior to the interview was planned or not.

The positive effect of parenthood on the self-esteem, a fact mentioned in many of the interviews, need not necessarily be considered a factor motivating the having of children. It is, namely, possible that the reasons for having the child were quite different, but on having had it and on becoming a parent, people have also felt a rise in their self-esteem. It is very difficult to distinguish cause and effect in experiences connected with the having of children.

The qualitative material based on the parents' self-evaluation does not provide evidence in the determination of the temporal relations between the factors mentioned. A similar finding to this, found in an earlier study, showed that in many cases the experience of giving birth boosts a woman's self-esteem both as a woman and as a wife, and only on rare occasions does it weaken this feeling. The data in this study shows that a man's self-esteem is also increased on his becoming a father.

The following two parents' comments are given as examples of the effect of childbirth upon a person's self-esteem:

»I had one wish of life before I was married, also after my marriage, a wish connected with self-acceptance: will I have any children and can I have any children, and is this the way to life as a worthwhile human being? It was sometimes a very important question. With the first child, it was whether she'd become pregnant .... (Mother: and get a healthy baby) ... It must certainly have been quite an important question to many a man before me. I don't know how many have stopped to think about it . . . (Mother: Many a woman must suffer if she couldn't have children).»

(man, 31, 2 children) 
"Somehow they boost your self-esteem, when you find you can have children and you have the ability to care for them.»

(woman, 29, 2 children)

Among the factors increasing one's self-esteem, in addition to demonstration of one's worth by having children (and possibly one's worthlessness in cases where for one reason or another there are no children) some parents mention aspects linked to an increase in one's sphere of influence such as »being needed by someone", " attaining a new level in the human life span» and »being accepted by such adults as already have children». Especially many parents with their first child stated that they experienced satisfaction in attaining one important goalpost in human life on having the child. Some mentioned having experienced social pressure to have children after having been married for some time and not having been able to have a child.

\section{Children as bringers of zest to life and as security in old age}

Many of those interviewed felt that children meant a brightening up and a stimulation to an otherwise monotonous life. The observation of the child's development in particular was mentioned as a pleasant factor in the enrichment of the parents' lives. The experience of children as »brightening up otherwise dull lives» might possibly refer to parenthood providing life win content and purpose; in this case parenthood obtains a broader, philosophical meaning.

Some parents said they felt their children disciplined them (the parents), this meaning that on having children, parents found it easier to give up selfish aims and habits. Responsibility for their children has often meant a considerable change for the parents, both in their personal set of values and in their living habits. Despite limits imposed by day care problems, parenthood seems to mean enrichment in the experience of most people.

Examples of comments by parents who experienced children as an added enrichment of life are as follows:

»Children bring an element of optimism in the future ... (H: How?) When you follow their development, there are so many enjoyable moments and it is so nice to be there to experience them. It cheers up the parents as well.»

(man, 30, 3 children)

»In all, a child does give color to everyday life. At least, looking at it from the point of view of a mother, seeing one's child grow and develop is very satisfying.»

(woman, 21, 1 child)

»It kind of gives it (life) content. It's a kind of pacifying situation: you don't gad about all day, you give a little thought to what you do. It's been that way ever since I was a kid, thinking that one day I'll have kids of my own. I don't know, there's s o m e t h i n g fascinating about it.»

(woman, 32, 3 children)

In addition to the increase in human worth and the brightening up of life, the corpus contained a third instrumental meaning: the experiencing of children as security in old age. Only a few of those interviewed mentioned this factor which did not seem to have a particularly important status in the experience of most people. Finland, for example, is in the forefront of the world as regards the social security of the aged; this could also be a factor in people not regarding children as »someone to care for them in their old age». In other types of society, regarding children as security in old age may be considerably more general. Let it also be said that of the 80 people interviewed not one expressed economic reasons as reasons for having children (this being one of the values cited by Hoffman and Hoffman (1973)). 
Children as old age security, mentioned by 10 interviewees in all, appeared in the corpus in the following manner for instance:

"We'd be quite alone if it was just the two of us, and no one would come and visit us when we were $50-60$ years old.»

(man, 37, 3 children)

"I suppose it is quite natural to have children . . . And then, of course, you do think of your old age: you wouldn't be on your own then. . . . It's quite natural.»

(woman, 36, 2 children)

"If we are to be a family, then we must have children. For several years we didn't . . . when the time's right, then we said we'd have kids . . . so that they'd come and visit us when we were old.»

(man, 33, 2 children)

\section{Discussion}

In his later works Ludwig Wittgenstein employed the concept "form of life» (Lebensform), by which he referred to the customs people abided by. According to Wittgenstein, forms of life which vary from culture to culture should not be explained. Instead they should be described and understood. Having children is one aspect of the form of life. Following Wittgenstein's train of thought we could say that it makes no sense to look for the reasons why people have children; what w o u l d make sense would be to describe the forms of life associated with having children. This article attempts to describe these from the aspect of the meanings ascribed to children.

From the point of view of demography, a study such as this is necessary even though the aim was not to construct a theory to explain why people have children. The demographic import of this study is in enabling us to understand (Verstehen) parenthood, values, experiences and meanings connected to having children. This in turn creates conditions for an ever deeper and more appropriate population policy and counseling services dealing with problems with the birth rate.

The Finnish birth rate has, during the 1970s been among the lowest in the world. According to some forecasts, the population of the country will begin a downturn before the year 2000. From the point of view of the development of society, a low birth rate means at least as great a problem as an excessively large increase in population. As is shown by this study, parenthood and having children are basically concerned with deep-reaching human values. The family policy practised in society is something that could have a natural effect on birth rate and should thus be aware of these value dimensions of parenthood and family life.

The »quality of parenthood» and by way of the latter the whole way of life of the culture concerned are closely connected to the general attitude held in the society toward children. The descriptions of the meaning attached to children in the data of this study indicate that the family-centered, »familistic» way of thinking is characteristic of many Finnish parents with small children. The study upon which this article was based also demonstrated the fact that many parents experience a sense of conflict between family policy as practised by society and their own child- and family-centered sets of values. A particular object of criticism was the lack of sufficient economic support for families where the wife stays home to look after the children.

The low birth rate in Finnish society is a population policy problem which, to be solved, requires firmer measures in family policy supporting families with children. This study did not look into the question of why people do not have more than one or two children. The data does, however, lead us to believe that people would be willing to have more children if only certain problems of a financial-practical nature burdening families with children were solved. Earlier studies also show that the ideal 
number of children in a Finnish family on the average exceeds the 2.3 children which number is the prerequisite for a good turnover of population. At the moment the average number of children per family is 1.9 .

On the basis of the comments given by the parents interviewed about the meaning their children held for them it may be claimed that child- and family-centredness is a naturally innate pattern of thought in man. This way of thinking can be further reinforced by family training based on values, in which case family training also acquires demographic dimensions.

By helping parents to attribute positive significance to parenthood by creating positive experiences of parenthood, value-centered family training can, in addition to family policy measures supporting families with children financially, have a significant influence on a rise in the Finnish birth rate.

\section{References}

Blumer, H. R. (1969). Symbolic interactionism. Perspective and method. Englewood Cliffs, New Jersey.

Burr, W. R.; Leigh, G. K.; and Constantine, J. (1979). Symbolic interaction and the family. In: Contemporary theories about the family edited by W. R. Burr et al. Volume 2. The Free Press, New York.

Grönfors, M. (1982). Kvalitatiiviset kenttätyömenetelmăt. WSOY, Porvoo.

Hoffman. L. W. and Hoffman, M. (1973). The value of children to parents. In: Psychological Perspective on Population edited by J. T. Fawcett. Basic Books, New York.

LaRossa, R. (1977). Conflict and power in marriage. Expecting the first child. Sage Publications, Beverly Hills.

LaRossa, R.; and LaRossa, M. M. (1981). Transition to parenthood. How infants change families. Sage Publications, Beverly Hills.

LeMasters, E. E. (1974). Parents in modern America. A sociological analysis. The Dorsey Press, Homewood, Illinois.

Rapoport, R.; Rapoport, R. N.; and Strelitz, Z. (1977). Fathers, mothers and society. Basic Books, New York.

Rock, P. (1979). The making symbolic interactionism. Rowman, London.

Rossi, A. C. (1968). Transition to parenthood. Journal of Marriage and the Family 12: 26-39. 